\title{
The Spectacular Mundane in the Films of Studio Ghibli
}

\section{Zoe Crombie}

\author{
Volume 2, Pages 1-26
}

\begin{abstract}
This article examines how Studio Ghibli constructs the mundane activities shown in their films as spectacular. Looking at the history of the ways in which domestic and routine events are depicted in Japanese animation, I will use various methodologies, beginning with formalism and phenomenology before moving on to feminism and Marxism to critically analyse several Ghibli films as case studies $-M y$ Neighbors The Yamadas (1999, Hōhokekyo Tonari no Yamada kun), Only Yesterday (1991, Omoide Poro Poro), and Howl's Moving Castle (2004, Hauru no Ugoku Shiro). Using these methodologies, the films are placed into a broader cinematic context, and the filmic legacy of their treatment of the mundane is explored.
\end{abstract}

Keywords: Ghibli, mundane, anime, spectacle, domesticity

Author Bio: Zoe Crombie is a researcher in film and anime studies at Lancaster University, UK. She is currently investigating Studio Ghibli's European adaptations in the context of transcultural exchange, and can be found watching Howl's Moving Castle on repeat.

This work is licensed under a Creative Commons Attribution-NonCommercial 2.0

\section{Generic License}




\section{Introduction:}

To begin, I would like to clarify my usage of the words 'spectacular' and 'mundane', upon which this article depends. Rather than implications of boredom implied by some definitions, I am using the term 'mundane' to mean 'characterised by the practical, transitory, and ordinary'1 - domestic chores and other everyday occurrences, for example. Similarly, while spectacle is often associated with excitement, I intend to use the definition of the term that I believe relates most closely to its use in film scholarship: 'something exhibited to view as unusual, notable, or entertaining' ${ }^{2}$. Whilst existing research on mundane and domestic activities within Japanese cinema certainly exists--most notably David Bordwell's investigation of the films of Ozu Yasujiro3, which heavily centre around domestic situations--there is little currently that specifically focuses on anime. This is especially fascinating as, outside of academia, this is an attractive element of anime for many viewers, to the extent that the popular website TV Tropes describes the concept 'Mundane Made Awesome'4 that features often in slice of life anime TV shows. However, elements that I will refer to as 'fantasy' are still a significant aspect of Ghibli works, so I will define this term here as 'a creation of the imaginative faculty' 5 , in contrast to what is possible and plausible in reality. Ultimately, my goal is therefore to bring an exploration of the mundane as spectacular into animation scholarship, especially as it pertains to the works of Studio Ghibli, who often utilise the spectacular mundane within their broader narratives.

\section{Domestic Situations in Anime}

To understand the domestic scenes in anime that place a significant value on the mundane, we must first examine the ancient Japanese religion of Shintoism that began in the Yayoi Period $(400 \mathrm{BCE}-300 \mathrm{CE})^{6}$ and that one could argue has strongly 
influenced this tendency. The 'essence' of Shintoism is put forward by scholar and practitioner of Shinto, Yamakage Motohisa, as 'our relationship and interdependence with Kami' defined as 'the powers of the spiritual dimension'7. Rather than remaining in a separate spiritual realm inaccessible by living humans, as is the case in religions such as Christianity, the interaction with Kami through mundane activities is a key element of celebrating and honouring the Gods. For instance, 'charm cards', or omamori dedicated to specific Kami, are given to people like drivers and students for luck, removed from any sacred context ${ }^{8}$. Though the importance of various Kami is considered hierarchical (with the sun goddess Amaterasu at the top of this chain), according to the $18^{\text {th }}$ century Japanese scholar Norinaga Motôri they can still be found within 'all other awe inspiring things'9, even inanimate objects such as mountains 10. This suggests that a spectacular reading of the mundane has been present in Japanese culture for centuries, as 'virtually any thing' ${ }^{11}$ could be considered Kami.

Unsurprisingly, references to Shinto shrines and Kami have appeared explicitly in a number of films by Studio Ghibli, particularly those set in rural, early $20^{\text {th }}$ century Japan like My Neighbor Totoro (1988, Tonari no Totoro) ${ }^{12}$. When the family arrives at their new home at the start of the film, the youngest daughter Mei notices the disappearance and reappearance of 'soot sprites', sentient pieces of dust that have taken up residence in the home. These creatures are not described as Kami, but the divine powers they possess are heavily implied by how they appear out of thin air in flurries, inanimate objects - albeit with anthropomorphised faces - that somehow contain life. Eventually, these creatures leave the house when the family ritualistically laugh while bathing together, evoking 'cleansings' within 'flowing water'13 that occur frequently within Shintoism. These nods to practices within Kami worship, when 
combined with the awe and excitement of the children at seeing an object as simple as a dust bunny, suggest that much of the spectacle in Studio Ghibli films may be steeped in and influenced by these religious practices.

Mundane actions of the everyday have a particularly privileged position in the world of early cinema, with simple actualities like The Arrival of a Train ${ }^{14}$ often being referred to as some of the first cinematographic works ever made. This extends to the first anime ever created, Katsudo Shashin ${ }^{15}$. The film is three seconds long, depicting a boy in red, black, and white as he writes the characters '活動写真' (romanised as 'katsudo shashin', meaning 'moving picture') on the background. He then turns to the spectator to remove his hat and bow down - a simple series of gestures that exists only to display the spectacle of this new medium. In another significant development in the history of anime, the first Japanese animation to have synchronised sound was a small-scale romantic comedy focused on a small scale, domestic issue. The film, Chikara to Onna no Yo no Naka (1933, Within the World of Power and Women) ${ }^{16}$, centres around a husband and his overbearing wife, whose nagging leads him to have an affair with his typist. This misogynist plot may be a far cry from the feminist readings of Ghibli which will be discussed later in this article, but the fixation on simple human interactions within a familiar domestic sphere remains.

Prior projects by Studio Ghibli's two founding directors, Takahata Isao and Miyazaki Hayao, also abound in a celebration of the simple everyday. As what is arguably Takahata's most well-known pre-Ghibli work, the series Heidi, Girl of the Alps (1974, Arupusu no Shôjo Haiji) ${ }^{17}$ has a focus on the simple pastoral life of its titular protagonist, a young orphan girl taken in by her extended family. Within the first episode of the show, Heidi undertakes activities like hiking and goat herding, all 
rendered in a softly coloured, minimalist aesthetic. While the plot itself involves elements as sensationalist as murder, the visuals of the show provide an outlook that maintains the calm tone of Heidi's everyday life. By choosing to 'emphasize quotidian actions and emotion rather than fantasy or adventure'18, an inherent value is placed on Heidi being able to interact with her home environment at her own pace. A similar value is put onto the everyday in Miyazaki and Takahata's earlier and similar short Panda! Go Panda! (1972, Pando Kopanda) ${ }^{19}$. Although it features the fantastical idea of being raised by a large, anthropomorphic panda, this novelty primarily exists to show the orphaned protagonist able to engage with simple domestic practices, such as making dinner for her new family.

Takahata's My Neighbors The Yamadas (1999, Hōhokekyo Tonari no Yamada kun $)^{20}$ departs from the usual Ghibli house style by utilising a simplistic comic book aesthetic, often rendered solely through thin black lines with a watercolour finish, that was achieved through digital animation. The film is one of the earliest examples of a feature animated film that was made entirely digitally rather than traditional methods such as cell animation used in prior Ghibli works. This allows for a clean aesthetic reminiscent of the simplistic 'emakimono' style of drawing in Japan which 'freed' artists from 'over illustrative details' in depicting people ${ }^{21}$. This was markedly different from the complex use of CGI and 3D animation films by Pixar emerging at the same time - Toy Story $2^{22}$ the same year, for instance. The plot of the film features few fantasy elements, instead fixating on the goings on of an average Japanese family. As somewhat of a visual outlier in the Ghibli filmography, I believe it both aesthetically and thematically intensifies and abstracts the notion of domesticity in the Studio's films to its purest form. Rather than weaving a focus on the mundane throughout a 
wider narrative, the mundane is the bulk of the narrative. Here, the Ghibli preoccupation with everyday activities reached its peak, as domestic Japanese customs and familial relationships are given room to exist only for themselves, rather than to forward a more eventful plot. Rather than a linear cause and effect narrative, Takahata utilises a more episodic structure. Each short segment has a grandiose, tongue in cheek title such as 'A Family Torn Apart' or 'Patriarchal Supremacy Restored' - these humorously contrast with the mundane content of the shorts.

The way in which the mundane is given spectacular treatment by Takahata in the film is exemplified in a later sequence of the vignette 'Marriage Yamada Style', where a domestic situation plays out into a performance that other characters in the scene comment upon. Takashi, the father, and Matsuko, the mother, are fighting for control of the TV, the former to watch sports and the latter to watch a film. Unlike the strangely proportioned and exaggerated designs of the Yamadas, the sports stars shown on the TV screen have been animated through the rotoscope technique, in which actual photographic footage is traced over to create a realist appearance of movement. The fact that this screen is framed centrally also helps in the treatment of the broadcast as spectacular, until the hypothetical camera eventually pulls out to reveal that this is only a minor focus in a larger scene, and that Takashi's gaze is fixated on a newspaper, implying that these small spectacles can be found throughout the household. When the argument breaks out between Takashi and Matsuko, the former attempts to block the TV remote's sensor with his paper, and the ensuing fight resembles a ballet in its fluidity of movement. The punchline that ends the sequence is shown via the camera once again pulling back from the TV, to reveal Shige (the grandmother) and Nonoko (the daughter) watching their family members for 
entertainment and exchanging the following lines: 'now no one can watch TV', 'this is much more interesting'. As well as layering the gazes of the characters for comedic effect, the scene also uses the idea of spectatorship to convey the main thesis of the film. Through this sequence, My Neighbors the Yamadas posits that the everyday goings on of a family can often be more exciting and compelling than what is typically constructed as spectacle, e.g. a sports game or mainstream movie.

\section{Experiencing the Mundane Anew}

In order to effectively analyse how domesticity and the mundane in Studio Ghibli films is depicted as desirable and enjoyable, I will employ multiple methodologies. Besides the ideological approaches such as feminism and Marxism which we will get to later in this article, I will first explore the formal elements of film through the lens of defamiliarization and phenomenology. The first method belongs to the school of formalism, which posits that everything needed to understand a text can be found within it. Conversely, the latter is concerned with the relationship between the human subject and film object, and the subjective experience that can come from viewing any kind of art. By using these theories in conjunction, I hope to uncover first how Ghibli defamiliarizes the domestic to be seen anew, and then to understand how this aids the sensual, subjective joy that is generated when watching these mundane scenes.

Defamiliarization, a concept established by the Russian formalist movement, specifically Viktor Shklovsky, is a useful tool in examining how the films of the studio reframe mundane scenarios. Ghibli often encourages their audience to re-examine events in their day to day lives with a perspective removed from their usual repetition and familiarity. In his essay 'Art as Technique'23, Shklovsky identifies that 'as 
perception becomes habitual, it becomes automatic'24, giving the example of 'speaking in a foreign language for the first time'25 compared to when it eventually becomes second nature. Therefore, his idea of 'defamiliarization' in art (poetry as the given example in his essay) is about recreating the original experience of interacting with an object. I argue that this idea is imperative in studying depictions of the mundane onscreen, as representations of familiar actions can be reintroduced to audiences in a way that allows them to appreciate them anew - letting them 'make the stone stony' 26 again.

As an art form reliant entirely on pictorial representation in motion, I argue that two-dimensional animation is a key medium in terms of its ability to defamiliarize. By abstracting a familiar image into a collection of colours and lines, the viewer is unconsciously forced to analyse the frame and determine what exactly is being depicted. This then challenges them to newly recognise an image that has previously been second nature, in a way that direct photographic representation may not. This is exemplified in Eisenstein's notion of 'plasticity', defined by Pasi Valiaho as the ability of animated forms to 'at any moment [be] susceptible to stretching, bending and rebounding, if not to total shape-shifting' ${ }^{27}$. The shapes of animation are dynamic and undefined by nature - automatically defamiliarized by their own instability, even when not in motion.

Though defamiliarization is helpful and relevant to this article as a standalone method of filmic analysis, I will be utilising it in conjunction with a method from another framework in order to effectively study why domestic moments in Ghibli films are both freshly presented and sensually appealing. Phenomenology is a framework concerned with subjective, sensual interpretations that is defined by theorist Robert 
Sokolowski as 'the study of human experience'28. Rather than studying the formal mechanisms of a film in isolation, phenomenology is interested in how individual viewers respond to a work of art. This is exemplified in Edmund Husserl's process of phenomenological production, which involves two parts: performing the 'epoche' and reduction proper. The first is defined by casting aside preconceptions about an object or situation in order to 'examine them in a new light, namely in their appearance'29. The second step is to investigate your newly uncovered reactions, observations, and sensory experiences of the object: 'our thematization of the correlation between subjectivity and world' ${ }^{3}$. Much like defamiliarization, the result is a fresh feeling towards an object that has become everyday. But while defamiliarization takes place solely as part of the film text, phenomenological reduction via performing the epoche is about the relationship between subject and object.

As a film focused on the commonplace yet highly sensuous memories of its protagonist, Only Yesterday (1991, Omoide Poro Poro) ${ }^{31}$ is an excellent candidate for analysis through both formalist and phenomenological lenses. With a narrative that takes place over two time periods, that of the protagonist Taeko as both a young girl and a grown woman, the film is concerned with the everyday experiences that have shaped her worldview, from early discussions of puberty to the excitement in trying her first pineapple. However, these experiences seem to have been selected by Takahata less for their significance as standard milestones (first words, graduation, etc.) and more for how their emotional and sensual power has forced Taeko to etch them into her mind as the most important, formative moments in her early life. This narrative structure alone reinforces the privilege of the mundane afforded to many 
Ghibli productions, allowing the simple, understated moments that have made up the life of a young woman to constitute the entire runtime of a film. This is highlighted effectively in the Japanese title of the film, Romanised as 'Omoide Poro Poro', which translates to 'Memories Come Tumbling Down'. In this sense, Only Yesterday fits Gilles Deleuze's notion of the 'time image' ${ }^{2}$, in which a film focuses on identification with the protagonist's subjective experience of time - a mode that further emphasises the importance of the personal, and therefore often the ordinary.

The most evident scene for analysis in the film is the moment in which Taeko remembers eating a pineapple with her family for the first time, her sensory recall being the primary purpose of the scene. The subjective nature of memory is signalled throughout the film by the faded, pale quality of the flashback sequences. Rather than utilising black and white, a conventional choice for this type of scene, Takahata makes these scenarios seem distant and muddied via a more sepia toned palette. However, in making these scenes less accessible to the audience, Takahata invokes a sense of subjectivity in Taeko that we are privy to, paradoxically making the scene more intimate by constructing it more broadly. By aligning us with Taeko with this technique, as well as consistent spatio temporal alignment throughout the entire runtime, we are inclined to think sensually of the aroma of pineapples when she breathes in, taking in the smell of the fruit. As this mundane object is unfamiliar and unusual to young Taeko as a Japanese girl in the 1960s, it is defamiliarized by both the narrative and by the 'camera' lingering upon her family's interaction with it. For instance, the closeup of the pineapple being cut while her family are speaking places it at the top of the visual hierarchy, beyond even the communication between characters. As she takes a bite, we are also invited to imagine what this slice of pineapple might 
taste like, the sensory evocation in the scene lending even greater importance to a simple moment of novel domesticity. Her disappointment at the unripe pineapple is eventually revealed to be at the heart of this formative moment, and we can feel this frustration as viewers, especially if we have already recalled the taste along with her, and the bathos of the scene solidifies the impact of seemingly unimportant moments.

Moving away from depictions of food, the way in which the farming routine is depicted is also very sensually evocative, encouraging the viewer to emphatically relate to the physical sensations of the characters. Takahata uses Taeko's voiceover to describe what she understands of the safflower farming process, allowing us to enter into her subjective experience. As well as explaining the process, the narration creates a connection between Taeko and the village girls who had done this before her, mentioning the pain they felt in picking the flowers without gloves. As well as providing an interesting perspective on the pain in women's labour, this ultimately superfluous detail encourages sensory alignment in Taeko when she reacts to the feeling of being pricked by the thorns. When performing the epoche on this particular scene, I was drawn to the extensive use of foley sound (picking the flowers, squishing them into containers, etc.) that gives an effect akin to synaesthesia. In hearing the sound of her pressing the flowers, viewers understand how they would feel to the touch, and are further immersed in the sensual elements of the process. The use of similes in the script - 'like liquid gold' - also seems to encourage phenomenological thought, allowing the viewer to also make subjective connections between the safflowers and what they have personally experienced. Defamiliarisation, much like in the pineapple scene, is brought forth through closeups and long takes, in this case of the safflowers themselves. By markedly observing the shape, colour and texture of the 
plant, we are placing a new significance on the nature depicted in the film, Taeko's description of their importance to the local economy granting them even greater value.

\section{Ideological Readings of Domesticity}

'Many of my movies have strong female leads - brave, self-sufficient girls that don't think twice about fighting for what they believe with all their heart. They'll need a friend, or a supporter, but never a saviour. Any woman is just as capable of being a hero as any man.' 33

This quote originates from an interview with Miyazaki for The Guardian from 2013, but has been shared across the internet by thousands as direct evidence of Studio Ghibli's feminist ideology as a studio. The concept of a 'strong female lead' is defined by Miyazaki not through physical strength, but by their compassion and a willingness to act on what they believe is morally right, suggesting that this form of strength is not entirely incompatible with conceptions of femininity. It would be remiss of me not to acknowledge that the mundane situations I have been analysing carry primarily feminine associations, occurring in the home or more broadly in the realm of the domestic.

Of course, it is important to ensure that any feminist perspective imposed onto the films of Ghibli relates specifically to Japanese forms of the movement. In the 1970 s and 1980s, when Miyazaki and Takahata's careers were beginning, the discussion around women's 'desire for control over their own reproductive capacity'34 was a key feminist issue. Simultaneously, there was a growing sense of resentment over the 'domestic labour' 35 that they were forced to undertake in the home. With this in mind, the choice of the Ghibli directors to primarily portray prepubescent girls or young women becomes particularly interesting - in their formative years, these protagonists 
almost never express a desire to procreate, and their character arcs often leave their futures open. However, this does not equate to a wholesale rejection of femininity; though some protagonists, like San from Princess Mononoke (1997, Mononoke Hime) ${ }^{36}$, are shown to reject elements of traditional femininity like politeness and an aversion to violence, I'd argue that most actually conform to these ideals. For example, Marnie from When Marnie Was There (2014, Omoide no Mānī) ${ }^{37}$ and Sheeta from Castle In The Sky (1986, Tenku no Shiro Rapyuta) ${ }^{38}$ both have conventionally feminine appearances (long hair, dresses, long eyelashes, etc.) and act within the rules of traditional etiquette. Narratively, Only Yesterday presents many of the conventionally feminine experiences of Taeko (periods and arguing with her sisters over new clothes). To be clear, this is not to imply that they are inactive in their own narratives because of their femininity; I argue that one of Ghibli's more recognisable features is its treatment of the feminine as powerful, particularly that of workingclass women.

Understandably, the feminist readings mentioned tend towards looking at the heroism of the female characters when removed from a domestic context - for instance, when in battle or plunged into fantastical worlds. However, this context is nonetheless frequently depicted in numerous Ghibli films and suggests a complex relationship between its many female protagonists and their expected roles in society. This both meshes with and complicates the negative connotations of being just a housewife' 39 put forward by second wave feminists like Betty Friedan. Although the female characters have agency in the narrative outside of the home, an undeniable joy is taken in mundane, domestic work by characters of all genders. In depicting this work 
as potentially fulfilling and enjoyable for anybody, the filmmakers of Ghibli are advocating and romanticising a widely disparaged form of labour - 'women's work'.

Intersectionality in feminist theory, in particular its 'ontological complexity' is defined by feminist scholar Ange-Marie Hancock as 'the idea that analytical categories like "race", "gender", "class", and the hegemonic practices associated with them [...] are mutually constitutive, not conceptually distinct'40. For instance, women are considered to be oppressed under patriarchy, and the working class are similarly oppressed under capitalism, so working-class women possess a unique set of struggles and experiences. The domestic scenes of Ghibli films are especially interesting from the perspective of the intersection of gender and class, as while labour undertaken in the home is often feminised, the studio frames this positively, empowering the female and working-class characters of its films. This sometimes comes in the form of framing male characters with traditionally feminine attributes in a positive light, rather than presenting female characters with masculine traits as is often lauded as progressive. By portraying the feminine domestic in an ideal light, Ghibli posits that a conventionally feminine outlook on life may be more beneficial than a masculine one. This empowers all kinds of people regardless of background to take joy in their everyday and discredits arbitrary boundaries of gender and class.

As a Studio Ghibli film with a female protagonist that eventually settles down into a family with her significant other, whose name is featured in the very title of the film instead of hers, Howl's Moving Castle (2004, Hauru no Ugoku) ${ }^{41}$ displays how domesticity can be portrayed positively through an intersectional feminist and Marxist understanding. Much like the other case studies I have provided thus far, this film also includes numerous scenes of domestic labour irrelevant to plot progression. I argue 
that this serves to romanticise and idealise these typically feminine processes, making 'women's work' broadly appealing. Even the narrative structure seems to uphold this: rather than maintaining the pace by building towards various spectacular set pieces, it moves slowly, the war existing more as a barrier to domestic joy than as an aweinspiring event. The purpose of this widespread masculine threat is ultimately to bring forth a valuing of the intimate feminine domestic. Explaining this, Cheng-Ing Wu states that 'if the poetics of space optimizes the ideal of the universal human yearning for peace and for an integrated family, the most fearful threat to this is war'42. Though there are scenes throughout the film (that I will describe below) that effectively exemplify how exactly Miyazaki achieves this, it can be summarised by the way he chooses to end the film. Rather than ending the war through a total victory against an identifiable evil, the conflict subsides through democracy, with the characters not celebrating, but quietly and contently enjoying their new life as a family unit.

In order to later subvert the gender norms established as part of the fantasy world of Howl's Moving Castle, Miyazaki begins by including a scene in which Sophie's mundane life is threatened by a potentially violent masculinity. On her way to meet her sister at the bakery, she is cornered in an alley by two soldiers, depicted from a low angle, who refer to her as 'a little mouse' to imply she is prey to be toyed with. Before this progresses any further (though older audiences may understand the more sinister implications of this moment), a new character arrives behind Sophie, their face partially obscured. While both voice actors for the character (Christian Bale and Takuya Kimura) utilise a low, confident register, indicating masculinity, their slender frame and long, elegant clothes suggest androgyny, especially in contrast to the uniforms and facial hair of the soldiers. The character, later revealed to be Howl, 
condescends to the soldiers before using magic to force them to frog march away, a parody of their brash masculinity that shifts the tone from threatening to absurd. As the camera pans up to Howl's face, we see that his hair is long and light, and that he is wearing earrings and a necklace. This combination of gender signifiers suggests that Howl is not a slave to performing masculinity - while male, the way he appears removes the threat of masculine violence. The fact that he 'saves' Sophie in this scene could be interpreted as upholding stereotypical gender roles. Even so, I would argue that Howl's position as Sophie's more feminine saviour actually serves to highlight certain values associated with femininity that anyone can embody - namely, pacifism and domestic harmony.

An early scene of domestic harmony comes in Sophie's first interaction with Howl as an old woman, as she attempts to prepare breakfast for the family. Initially, this scene appears to comply with conventional gender roles: Sophie, the only woman in the 'family' and the oldest one there, undertakes the domestic duties, claiming she has her 'work cut out for her'. Although Howl's arrival into the home initially fits within these roles, as he appears to be weary from some unknown work, the situation is subverted when he insists on taking over the cooking, much to Sophie's apparent confusion. His expression changes to be visibly brighter, implying that a kind of regenerative effect can be produced from domestic work beyond the physical. This is emphasised by the visual treatment of the food being cooked - much like scenes from the previous case studies, the detailed foley sound and vibrant tones, as well as the closeup shots, invite you to consume the image sensuously. Howl's willingness to undertake this typically feminised domestic labour, as well as his natural talent at doing so, removes the stigma of performing labour beyond the confines of your gender, 
providing a foundation on which Miyazaki makes 'women's work' appealing to all. This subsequently implies that cleaning up the remainder of the house will bring him closer to contentment; indeed, this is true at the end of the film, in which the castle is in its best shape, and Howl is at peace.

\section{Responses to Ghibli's Depictions of Domesticity}

One way in which the impact of Ghibli's treatment of the mundane can be measured is through an analysis of the ways in which fans of the $s$ tudio are able to interact with their creations. Beyond the critical acclaim and international popularity the studio has received, one breakout feature of the films in particular has received an amount of fan attention disproportionate to the onscreen time it receives: food. As discussed earlier, scenes involving food as the subject matter are often given a defamiliarizing and highly sensual treatment, which has led to enormous online popularity (for example, viral Tweets that have amassed over 300,000 likes43). Interestingly, this includes various recipe blogs that attempt to recreate the food depicted in Ghibli films, most notably En93Kitchen 44 who gained over one hundred thousand followers posting images of Ghibli dishes she made in real life. To an extent, this confirms that the films have a phenomenological impact, leading people to want to experience the sensations they achieve through watching the films more directly and physically. Simultaneously, the production of yet more images of food based on Ghibli's creations suggests a desire to see mundane objects as spectacular, evident in the popularity of food blogs and videos with which Ghibli may hold an aesthetic and thematic similarity.

Despite an ongoing distribution deal with Disney, a company known for its merchandising and vertical integration, Studio Ghibli has maintained an image 
disconnected from consumerism, and yet still heavily associated with the everyday. Though the studio itself has produced some merchandise, the vast majority of Ghibli products available online are unofficial and unlicensed, using iconography like Totoro and the soot sprites in an attempt to appeal to fans of the films and children more broadly. This suggests a desire from viewers to integrate imagery from the $\mathrm{s}$ tudio into their domestic lives - a product like a non-licensed Totoro tea towel, for instance, seems to harken back to relevant images of cleaning common to many of their films. This brand image beyond the films is also cultivated by the Ghibli museum - once again, an interesting comparison with Disney, whose attraction is the largest theme park in the world. This museum is of a modest size, attracting only 650,000 visitors a year45 in comparison to Disneyworld's 52 million annual attendees ${ }^{46}$, further highlighting Ghibli's connection with the small scale and personal. This also stretches to the content inside of the museum; rather than traditionally spectacular rides, short films and exhibitions make up most of the attractions.

Unsurprisingly, the powerful legacy of Studio Ghibli looms large over anime films from other studios that have been released in recent years, resulting in homage via aesthetics and subject matter, including portraying the mundane as spectacular. For instance, as the initial choice to direct Howl's Moving Castle 47 , director Hosoda Mamoru holds a noted interest in the Studio emblematic of their revered place in the anime industry. I argue that similarities between the two directors can be found in Hosoda's film Mirai (2018, Mirai no Mirai)48 - its nomination for Best Animated Feature at the 2019 Academy Awards suggests a similarly transnational appeal. In this film, Hosoda uses fantasy imagery to explore the importance of family and domesticity from the perspective of a five-year-old boy and his small world. Although Hosoda has 
his own creative voice as a director, one can draw a clear line of influence from Miyazaki's common themes to works like Mirai, particularly in the use of a child protagonist who allows the audience to experience the domestic world from a fresh perspective.

Most notably, the legacy of Studio Ghibli is partially comprised of Studio Ponoc, which contains a group of animators who previously worked at Ghibli. While the most obvious similarities between the studios are the lush 2D animated aesthetic they share and the children's fantasy stories both frequently depict, I'd argue that Ponoc have also carried forward Ghibli's treatment of the ordinary into their own films. Though this truly comes to fruition in their anthology of short films Modest Heroes (2018, Chīsana Eiyū: Kani to Tamago to Tömei Ningen)49, their first feature Mary and the Witch's Flower (2017, Meari to Majo no Hana) ${ }^{50}$ foregrounds this with its focus on accessible nature, particularly the sensory aspects of gardening (much like Only Yesterday). As well as featuring a young female protagonist, a trope common to Ghibli works, the film is rooted in its pastoral setting, its title coming from the small blue flower that the protagonist Mary comes across while exploring the woods near her grandmother's house. This flower can be seen as an emblem for Ponoc's reinterpretation of Ghibli's spectacular mundane: the unassuming yet powerful phenomena that hide in the corners of our everyday life. Evidently, Ghibli's spectacular treatment of the mundane has resonated with both filmmakers and audiences alike. While their more conventionally spectacular imagery - that of flying castles and fantasy Gods - is still popular, this more unconventional treatment of the everyday has proved surprisingly evocative. As a result, there is a well-documented audience desire to recreate these 
images in their own domestic lives, as well as continued explorations of this theme from subsequent filmmakers who cite Studio Ghibli as their thematic source.

\section{Final Thoughts}

To draw any meaningful conclusions from this research, it is first important to explicitly acknowledge that the intended audience for Ghibli films is children. This has an important impact on the way their films are conceived, particularly in terms of their ability to inform and educate. While, as previously stated, there is a large portion of adult viewers (myself included) who enjoy actively integrating this domestic imagery into their lives, I understand this as more of a side effect of their treatment of the mundane than their target audience. The goal of these films has been plainly stated, with Miyazaki Hayao saying in interviews that his intention in making his animations is to tell children that 'it's good to be alive' 51 . This implies that the formal techniques used to create this spectacular mundane are intended to reassure the young target audience that contentment can be found in everyday life, not only in the fantastic spectacle that Ghibli depicts as its equal. The formalist and phenomenological readings that I examined from various scenes demonstrate how a viewer is invited to engage with domestic scenes on a deeper, more sensuous level than is usually requested, especially in the context of children's media. Therefore, I argue that these scenes exist at least partially to encourage a young audience to respond to the mundanity in their own lives with a similar focus and resonance (as is a precedent in Japanese culture through Shinto).

By romanticising domestic and everyday tasks in the majority of their works, Studio Ghibli provide an unusual reverence for the mundane that is simultaneously in line with Japanese tradition while still being symptomatic of more modern ideologies 
like feminism and Marxism. In primarily focusing on the lives of young, usually working-class women, Ghibli places an inherent value on their experiences. I argue that the fact that any of these characters received entire dedicated films is enough to suggest feminist intentions of empowerment. Rather than striving to be the most powerful, or to become the most wealthy, these characters seek happiness and contentment in a more low- key way that is drawn from a compassion for their surroundings, whether it comes in the form of saving the forest or enjoying a cup of hot chocolate. As the protagonists of children's media, this therefore gives the young audience an alternative model not just for womanhood but for children of all genders in approaching the seemingly duller elements of life when you are not in an extraordinary position. These scenes of the spectacular mundane exemplify the compassion that can come from domestic life, and the affection that so many people now hold for Studio Ghibli as iconic creators of animated masterpieces. 


\section{Notes}

${ }^{1}$ Merriam-Webster, "Definition mundane", 16 June 2020, https://www.merriamwebster.com/dictionary/mundane

${ }_{22}$ Merriam-Webster, "Definition spectacle", 16 June 2020, https://www.merriamwebster.com/dictionary/spectacle

3 David Bordwell, Ozu and the poetics of cinema. London: BFI Publishing, 1988

4 TV Tropes, "Mundane Made Awesome/Anime and Manga", TV Tropes.

https://tvtropes.org/pmwiki/pmwiki.php/MundaneMadeAwesome/AnimeAndManga?from=Munda neMadeAwesome.Anime

5 Merriam-Webster, "Definition fantasy", 16 June 2020, https://www.merriamwebster.com/dictionary/fantasy

${ }^{6}$ Helen Hardacre. Shinto: A History. Oxford University Press, 2016

7 Yamakage Motohisa, 2010. The Essence of Shinto: Japan's Spiritual Heart. Kodansha USA

8 Yamakage Motohisa, 2010. The Essence of Shinto: Japan's Spiritual Heart. Kodansha USA

9 Matsumura Kazuo, "Kami Definitions and Typology", Encyclopedia of Shinto. http://eos.kokugakuin.ac.jp/modules/xwords/entry.php?entryID=1

10 Matsumura Kazuo, "Kami Definitions and Typology", Encyclopedia of Shinto. http://eos.kokugakuin.ac.jp/modules/xwords/entry.php?entryID=1

11 Matsumura Kazuo, "Kami Definitions and Typology", Encyclopedia of Shinto. http://eos.kokugakuin.ac.jp/modules/xwords/entry.php?entryID=1

${ }^{12}$ Miyazaki Hayao, My Neighbor Totoro. Japan: Studio Ghibli, 1988

${ }^{13}$ Stuart D.B. Picken, Essentials of Shinto: An Analytical Guide To Principal Teachings. Westport: Greenwood Publishing Group, 1994

${ }^{14}$ Auguste Lumiere and Louis Lumiere, The Arrival of a Train. France: Societe Lumiere, 1896

${ }^{15}$ Katsudo Shashin. Japan, 1907

${ }^{16}$ Masaoka Kenzo, Chikara to Onna no Yo no Naka. Japan: Shochiku, 1933

${ }_{17}$ Takahata Isao, Heidi, Girl of the Alps. Japan: Nippon Animation, 1974

18 Violet Lucca, "Worldly Wise", Film Comment 54, No. 4 (2018)

19 Takahata Isao, Panda! Go Panda!. Japan: Tokyo Movie Shinsha, 1972

${ }^{20}$ Takahata Isao. My Neighbors The Yamadas. Japan: Studio Ghibli, 1999

${ }^{21}$ Tze-yue G. Hu, Frames of Anime: Culture and Image Building. Hong Kong: Hong Kong University Press, 2010

${ }^{22}$ John Lasseter, Toy Story 2. USA: Walt Disney Pictures, 1999

23 Viktor Shklovsky. "Art as Technique", Theory of Prose. 1925

24 Viktor Shklovsky. "Art as Technique", Theory of Prose. 1925, p. 2

25 Viktor Shklovsky. "Art as Technique”, Theory of Prose. 1925, p. 2

${ }^{26}$ Viktor Shklovsky. “Art as Technique”, Theory of Prose. 1925, p. 2

27 Pasi Valiaho, "Animation and the Powers of Plasticity", Animation 12, No. 3 (2017)

${ }^{28}$ Robert Sokolowski, Introduction to Phenomenology. Cambridge University Press, 2000, p. 2 
29 Dan Zahavi. Husserl's Phenomenology. Stanford: Stanford University Press, 2003, p. 51

3o Dan Zahavi. Husserl's Phenomenology. Stanford: Stanford University Press, 2003, p. 46

${ }^{31}$ Takahata Isao. Only Yesterday. Japan: Studio Ghibli, 1991

$3^{2}$ Giles Deleuze. Cinema 2: The Time-Image. London: Bloomsbury Publishing, 2013

33 Anna Cafolla. "Studio Ghibli filmmakers discuss gender onscreen and off" Dazed Digital, June 7, 2016. https://www.dazeddigital.com/artsandculture/article/31421/1/studio-ghibli-filmmakersdiscuss-gender-onscreen-and-off

34 Vera Mackie, Feminism in Modern Japan: Citizenship, Embodiment and Sexuality. Cambridge: Cambridge University Press, 2003, 192

35 Vera Mackie, Feminism in Modern Japan: Citizenship, Embodiment and Sexuality, Cambridge:

Cambridge University Press, 2003, 9

${ }_{36}$ Miyazaki Hayao, Princess Mononoke. Japan: Studio Ghibli, 1997

37 Yonebayashi Hiromasa. When Marnie Was There. Japan: Studio Ghibli, 2014

${ }^{8}$ Miyazaki Hayao. Castle in the Sky. Japan: Studio Ghibli, 1986

39 Betty Friedan, The Feminine Mystique. W.W. Norton and Co, 1963

40 Ange-Marie Hancock, Intersectionality: An Intellectual History. Oxford University Press, 2016, 71

${ }^{41}$ Miyazaki Hayao. Howl's Moving Castle. Japan: Studio Ghibli, 2004

${ }^{42}$ C.I. Wu, "Hayao Miyazaki's Mythic Poetics: Experiencing the Narrative Persuasions in Spirited Away, Howl's Moving Castle and Ponyo", Animation 11, No. 2 (2016)

43 Scullyxf. "is there anything more aesthetically pleasing than the food in studio Ghibli films", Twitter. https://twitter.com/scullyxf/status/1067500961554472960?lang=en

44 En93Kitchen. Instagram. https://www.instagram.com/en93kitchen/?hl=en

45 Eiga. “ジブリ美術館、来場者1000万人突破！宮崎駿監督が喜びのコメント”. March $31 ， 2020$ https://eiga.com/news/20170114/6/

${ }^{46}$ Magic Guides. 'Walt Disney World Statistics', Magic Guides. https://magicguides.com/disney-worldstatistics/

47 Miyazaki Hayao, Howl's Moving Castle. Japan: Studio Ghibli, 2004

${ }^{48}$ Hosoda Mamoru, Mirai. Japan: Studio Chizu, 2018

49 Yonebayashi Hiromasa, Yoshiyuki Momose, and Akiko Yamashita. Modest Heroes. Japan: Studio Ponoc, 2018

50 Yonebayashi Hiromasa, Mary and the Witch's Flower. Japan: Studio Ponoc, 2017

${ }^{51}$ Lucy Jones. “'it's good to be alive': The Studio Ghibli films are coming to Netflix at just the right time”. The Guardian. https://www.independent.co.uk/arts-entertainment/films/features/studio-ghiblinetflix-movies-my-neighbour-totoro-spirited-away-princess-mononoke-miyazaki-a9297181.html 


\section{Bibliography}

Cafolla, Anna. "Studio Ghibli filmmakers discuss gender onscreen and off” Dazed Digital, June 7, 2016.

https://www.dazeddigital.com/artsandculture/article/31421/1/studio-ghiblifilmmakers-discuss-gender-onscreen-and-off

Deleuze, Giles. Cinema 2: The Time-Image. London: Bloomsbury Publishing, 2013 Eiga. “ジブリ美術館、来場者1000万人突破！宮崎駿監督が喜びのコメント”. Accessed March 31, 2020 https://eiga.com/news/20170114/6/ En93Kitchen. Instagram. https://www.instagram.com/en93kitchen/?hl=en Friedan, Betty. The Feminine Mystique. W.W. Norton and Co, 1963 Hancock, Ange-Marie. Intersectionality: An Intellectual History. Oxford University Press, 2016

Hardacre, Helen. Shinto: A History. Oxford University Press, 2016 Hosoda, Mamoru. Mirai. Japan: Studio Chizu, 2018

Hu, Tze-yue G. Frames of Anime: Culture and Image Building. Hong Kong: Hong Kong University Press, 2010

IMDb. “Awards”, Hayao Miyazaki.

https://www.imdb.com/name/nmo594503/awards

Jones, Lucy. "'it's good to be alive': The Studio Ghibli films are coming to Netflix at just the right time". The Guardian. https://www.independent.co.uk/artsentertainment/films/features/studio-ghibli-netflix-movies-my-neighbour-totorospirited-away-princess-mononoke-miyazaki-a9297181.html

Katsudo Shashin. Japan, 1907

Lasseter, John. Toy Story 2. USA: Walt Disney Pictures, 1999

Le Blanc, Michelle, and Odell, Colin. Studio Ghibli: The Films of Hayao Miyazaki and Isao Takahata - Third Edition. Oldcastle Books, 2019 
Lucca, Violet. "Worldly Wise", Film Comment 54, No. 4 (2018)

Lumiere, Auguste and Lumiere, Louis. The Arrival of a Train. France: Societe Lumiere, 1896

Mackie, Vera. Feminism in Modern Japan: Citizenship, Embodiment and Sexuality. Cambridge: Cambridge University Press, 2003

Magic Guides. "Walt Disney World Statistics”, Magic Guides.

https://magicguides.com/disney-world-statistics/

Masaoka, Kenzo. Chikara to Onna no Yo no Naka. Japan: Shochiku, 1933

Matsumura, Kazuo. 2005. "Kami Definitions and Typology”, Encyclopedia of Shinto. http://eos.kokugakuin.ac.jp/modules/xwords/entry.php?entryID=1

Miyazaki, Goro. From Up on Poppy Hill. Japan: Studio Ghibli, 2011

Miyazaki, Hayao. Castle in the Sky. Japan: Studio Ghibli, 1986

Miyazaki, Hayao. Howl's Moving Castle Japan: Studio Ghibli, 2004

Miyazaki, Hayao. Kiki’s Delivery Service. Japan: Studio Ghibli, 1989

Miyazaki, Hayao. My Neighbor Totoro. Japan: Studio Ghibli, 1988

Miyazaki, Hayao. Ponyo. Japan: Studio Ghibli, 2009

Miyazaki, Hayao. Princess Mononoke. Japan: Studio Ghibli, 1997

Mayumi, Kozo. "The ecological and consumption themes of the films of Hayao

Miyazaki”, Ecological Economics 54, No. 1 (2005)

Picken, Stuart D.B. Essentials of Shinto: An Analytical Guide To Principal

Teachings. Westport: Greenwood Publishing Group, 1994

Scullyxf. "is there anything more aesthetically pleasing than the food in studio Ghibli films", Twitter. https://twitter.com/scullyxf/status/1067500961554472960?lang=en Shklovsky, Viktor. “Art as Technique”, Theory of Prose. 1925

Sokolowski, Robert. Introduction to Phenomenology. Cambridge University Press, 2000 
Takahata, Isao. Heidi, Girl of the Alps. Japan: Nippon Animation, 1974

Takahata, Isao. My Neighbors The Yamadas. Japan: Studio Ghibli, 1999

Takahata, Isao. Only Yesterday. Japan: Studio Ghibli, 1991

Takahata, Isao. Panda! Go Panda!. Japan: Tokyo Movie Shinsha, 1972

Teeuwen, Mark, and Scheid, Bernhard. "Tracing Shinto in the History of Kami Worship: Editors' Introduction”, Japanese Journal of Religious Studies 29, No. 3/4 (2002)

Thomas, R. Murray. Recent Theories of Human Development. Sage Publications, 2001

Valiaho, Pasi, 2017. 'Animation and the Powers of Plasticity', Animation 12, No. 3 (2017)

Williams, E. Leslie. "A Unity Of Pattern In The Kami Tradition: Orienting "Shinto" Within A Context Of Pre-modern And Contemporary Ritual Practice", Journal of Ritual Studies 14, No. 2 (2000)

Wu, C.I. "Hayao Miyazaki's Mythic Poetics: Experiencing the Narrative Persuasions in Spirited Away, Howl's Moving Castle and Ponyo", Animation 11, No. 2 (2016)

Yamakage, Motohisa. The Essence of Shinto: Japan's Spiritual Heart. USA:

Kodansha, 2010

Yasuda, Yuri. Treasury of Japanese Folktales: Bilingual English and Japanese Edition. Clarendon: Tuttle Publishing, 2014

Yonebayashi, Hiromasa. Mary and the Witch's Flower. Japan: Studio Ponoc, 2017

Yonebayashi, Hiromasa, Momose, Yoshiyuki, and Yamashita, Akiko. Modest Heroes. Japan: Studio Ponoc, 2018

Yonebayashi, Hiromasa. The Secret World of Arrietty. Japan: Studio Ghibli, 2010 Yonebayashi, Hiromasa. When Marnie Was There. Japan: Studio Ghibli, 2014 Zahavi, Dan. Husserl's Phenomenology. Stanford: Stanford University Press, 2003 